\title{
The Impact of COPD Exacerbations in the Year Following Pulmonary Rehabilitation: Secondary Analysis of a Randomised Controlled Trial
}

This article was published in the following Dove Press journal: International Journal of Chronic Obstructive Pulmonary Disease

\author{
Bruna Wageck (D) \\ Narelle S Cox (iD) ${ }^{1-3}$ \\ Christine F McDonald ${ }^{3-5}$ \\ Angela T Burge (D) ${ }^{1-3,6}$ \\ Ajay Mahal iD ${ }^{7}$ \\ Catherine $\mathrm{J} \mathrm{Hill}^{3,8}$ \\ Annemarie L Lee $\mathrm{Le}^{2,3,6}$ \\ Rosemary Moore ${ }^{3,8}$ \\ Caroline Nicolson 9,10 \\ Paul O'Halloran " \\ Aroub Lahham ${ }^{1-3}$ \\ Rebecca Gillies ${ }^{1,8}$ \\ Anne E Holland ${ }^{1-3,6}$ \\ 'La Trobe University, Melbourne, \\ Australia; ${ }^{2}$ Monash University, \\ Melbourne, Australia; ${ }^{3}$ Institute for \\ Breathing and Sleep, Melbourne, \\ Australia; ${ }^{4}$ Department of Respiratory \\ and Sleep Medicine, Austin Health, \\ Melbourne, Australia; ${ }^{5}$ Department of \\ Medicine, The University of Melbourne, \\ Melbourne, Australia; ${ }^{6}$ Department of \\ Physiotherapy, Alfred Health, Melbourne, \\ Australia; ${ }^{7}$ The Nossal Institute of Global \\ Health, The University of Melbourne, \\ Melbourne, Australia; ${ }^{8}$ Department of \\ Physiotherapy, Austin Health, Melbourne, \\ Australia; ${ }^{9}$ Department of Pulmonary \\ Hypertension, Alfred Health, Melbourne, \\ Australia; ${ }^{10}$ Physiotherapy Department, \\ Monash University, Melbourne, Australia; \\ "Department of Public Health, La Trobe \\ University, Melbourne, Australia
}

Correspondence: Anne E Holland Monash University, Central Clinical School, Level 6, Alfred Centre, 99 Commercial Road, Melbourne, VIC 3004, Australia

Tel +6I 399030214

Email a.holland@alfred.org.au
Background: Pulmonary rehabilitation is an effective treatment for people with chronic obstructive pulmonary disease (COPD), but its benefits are poorly maintained. The aim of this study was to evaluate the impact of COPD exacerbations in the year following pulmonary rehabilitation on outcomes at 12 months.

Methods: This was a secondary analysis from a trial of home versus hospital-based rehabilitation in COPD, with 12 months of follow-up. Moderate and severe exacerbations were identified using administrative data (prescriptions) and hospital records (admissions) respectively. The impact of exacerbations at 12 months following pulmonary rehabilitation was evaluated for quality of life (Chronic Respiratory Questionnaire, CRQ), dyspnea (modified Medical Research Council, mMRC), exercise capacity (6-minute walk distance, 6MWD) and objectively measured physical activity (moderate-to-vigorous physical activity, MVPA).

Results: A total of 166 participants were included, with mean age (SD) 69 (9) years and forced expiratory volume in one second $\left(\mathrm{FEV}_{1}\right) 49(19) \%$ predicted. Moderate exacerbations occurred in $68 \%$ and severe exacerbations in $34 \%$ of participants. Experiencing a severe exacerbation was an independent predictor of worse 12-month outcomes for CRQ (total, fatigue and emotional function domains), mMRC, 6MWD and MVPA (all $\mathrm{p}<0.05$ ). Participants who completed pulmonary rehabilitation were less likely to have a severe exacerbation $(29 \%$ vs $48 \%, \mathrm{p}=0.02)$. Severe exacerbations were more likely in those with

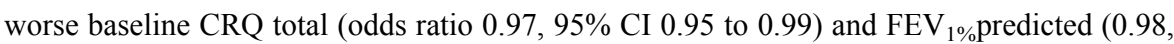
95\% CI 0.96 to 0.99 ).

Conclusion: Severe exacerbations occur frequently following pulmonary rehabilitation and predict worse 12-month outcomes. Strategies to maintain the benefits of pulmonary rehabilitation should address exacerbation prevention and management.

Keywords: COPD, exacerbations, pulmonary rehabilitation, long term maintenance, predictors

\section{Introduction}

Chronic obstructive pulmonary disease (COPD) is characterised by significant functional limitation and high mortality. ${ }^{1}$ Exacerbations of COPD are associated with disease progression and are one of the leading causes of hospital admission ${ }^{2}$ and death, ${ }^{3}$ highlighting the importance of interventions to prevent exacerbations or minimise their impact. Optimal treatment of COPD focuses on medication management, patient education, action plans for exacerbations, and pulmonary rehabilitation. ${ }^{4}$ Pulmonary rehabilitation, a program of exercise training and 
self-management education, is considered essential in the care of people with COPD. ${ }^{4,5}$ Pulmonary rehabilitation improves exercise capacity and quality of life and reduces symptoms and health-care utilisation in people with stable COPD. ${ }^{6}$ However, these improvements are not maintained long term. At 12 months following pulmonary rehabilitation, measures of exercise capacity, symptoms and healthrelated quality of life (HRQoL) have returned towards their pre-rehabilitation values. ${ }^{7,8}$ Maintenance exercise programs have not been effective in preventing this deterioration. ${ }^{9}$ It is possible that exacerbations in the postpulmonary rehabilitation period contribute to the lack of sustained benefit at 12 months, but this has not been systematically evaluated. Understanding the impact of exacerbations on long-term outcomes, and in whom exacerbations are likely to occur, may assist in designing more effective maintenance strategies following pulmonary rehabilitation.

The aims of this study were to: (i) document the frequency and severity of COPD exacerbations in the year following pulmonary rehabilitation; (ii) examine the impact of exacerbations on clinical outcomes at 12 months after pulmonary rehabilitation; and (iii) identify predictors of exacerbations in the year after pulmonary rehabilitation.

\section{Methods}

\section{Study Participants}

This is a secondary retrospective analysis of data collected from the HomeBase trial, ${ }^{8}$ a randomized controlled trial that recruited 166 people with COPD from two Australian tertiary hospitals between October 2011 and April 2014. The HomeBase trial compared a low cost, home-based model of pulmonary rehabilitation to a traditional centerbased program. The trial protocol and outcomes have been reported previously ${ }^{8,10}$ and the study protocol was registered (NCT01423227, clinicaltrials.gov). The multicentre study was performed in accordance with the principles stated in the declaration of Helsinki and approved by the Human Research Ethics Committees of Alfred Health (261/11 on 28 July 2011), Human Research Ethics Committees of Austin Health (H2011/04364 on 22 September 2011). Written informed consent was obtained from all participants. Potentially eligible participants were people with stable COPD referred to pulmonary rehabilitation at two tertiary hospitals in Melbourne, Australia. Eligibility criteria were a diagnosis of COPD
$\left(\mathrm{FEV}_{1} / \mathrm{FVC}\right.$ ratio $\left.<0.7\right)$, with a smoking history of at least 10 years and age 40 years or older. Exclusion criteria were a diagnosis of asthma, attendance at a pulmonary rehabilitation program in the last two years, a COPD exacerbation within four weeks prior to study enrolment (as previous studies show substantial recovery within this timeframe), ${ }^{11}$ or presence of any comorbidities which prevented participation in an exercise training program.

Comprehensive pulmonary rehabilitation was delivered in accordance with international guidelines ${ }^{12}$ and included aerobic and resistance exercise training as well as education and self-management skills. ${ }^{8}$ Full details of the rehabilitation interventions are published elsewhere, ${ }^{8,10}$ but briefly, participants randomized to center-based pulmonary rehabilitation received usual supervised pulmonary rehabilitation in a hospital outpatient setting twice a week, with encouragement to exercise at least another three times per week at home. Participants randomised to home-based pulmonary rehabilitation (HomeBase) received an initial home visit from a physiotherapist followed by seven, once-weekly telephone calls from a physiotherapist for progression of the exercise prescription and selfmanagement training. Participants in the HomeBase group were encouraged to exercise five days of the week for at least 30 minutes comprising aerobic and resistance training. Both pulmonary rehabilitation programs had a duration of eight weeks and participants recorded their home exercise participation in a diary. A previous publication reported between-group clinical outcomes, with equivalent effects for home and centre-based pulmonary rehabilitation at end rehabilitation and 12 months. ${ }^{8}$

\section{Exacerbations of COPD}

The number of moderate and severe exacerbations for each participant in the 12 months following pulmonary rehabilitation was obtained using data collected from the hospital medical records and Australian government Medicare Benefits Schedule and Pharmaceutical Benefits Scheme records. Detailed definitions of exacerbations can be found in Appendix S1 - Methods. An exacerbation was classified as severe if it resulted in a hospital or emergency department admission, ${ }^{4,13-15}$ or moderate if it resulted in filling of a prescription for oral corticosteroids (OCS) and/or antibiotics, ${ }^{13-16}$ in accordance with Global Initiative for Chronic Obstructive Lung Disease (GOLD) strategy classification for exacerbation severity ${ }^{4}$ (Table S1). It was not possible to identify mild exacerbations of COPD (change in symptoms with small change in management such as 
increased bronchodilators), as data for daily symptom changes were not collected during the trial. To be classified as a new exacerbation the event must have occurred more than 14 days following the previous event. ${ }^{13,17}$

\section{Outcomes of Pulmonary Rehabilitation}

Measures of exercise capacity, health-related quality of life and symptoms were obtained at baseline, after eight-week intervention period, and 12-month follow-up. Functional exercise capacity was measured using the six-minute walk test (6MWT), a valid measure of exercise capacity in people with COPD that is responsive to pulmonary rehabilitation. ${ }^{18}$ Health-related quality of life was measured with the selfreported Chronic Respiratory Disease Questionnaire (CRQ), ${ }^{19}$ a disease-specific measure which assesses the domains of dyspnea, fatigue, emotional function and mastery. Higher scores indicate better quality of life. The modified Medical Research Council Scale (mMRC) is a validated measure of the functional impact of dyspnea in people with COPD. ${ }^{20}$ Physical activity was measured in a subgroup of participants (home-based group $n=29$; center-based group $\mathrm{n}=38$ ) that wore the Sensewear armband (BodyMedia, Pittsburgh, Pennsylvania) after the completing the pulmonary rehabilitation program. Participants wore the armband 24 hours per day for a period of 7 days. ${ }^{21}$ To be included in the analysis, a minimum of 10 hours of wear time per day for four days was required. Data were collected minute-byminute of wear and analysed using proprietary software (Bodymedia V7.0). Intensity of physical activity was described in metabolic equivalents $(1 \mathrm{MET}=1 \mathrm{kcal} / \mathrm{kg} /$ hour) with each minute of wear allocated a corresponding physical activity level (sedentary $\leq 1.5 \mathrm{METs}$, moderate and vigorous physical activity (MVPA) $\geq 3$ METS). ${ }^{22}$ Physical activity was reported as total time (minutes) spent in MVPA per day; time spent in bouts of at least 10 minutes of MVPA and, time (minutes) spent sedentary whilst awake time per day. Completion of pulmonary rehabilitation was defined as attending at least $70 \%$ of planned sessions. ${ }^{8}$

\section{Statistical Analysis}

Data analysis was conducted using SPSS V.25.0 (IBM, New York). Descriptive statistics (mean and standard deviation (SD)) or median and interquartile range [IQR] or number (n (\%)) were used to describe frequency and severity of exacerbations in each group. Relative risk of having an exacerbation was calculated for dichotomous measures. Kaplan-Meier survival analysis was used to describe the time to first exacerbation after pulmonary rehabilitation. Clinical outcomes of interest changed from baseline (pre-pulmonary rehabilitation) to 12 months following pulmonary rehabilitation, in order to evaluate longterm benefits. Univariate analysis comparing outcomes in individuals who did and did not experience an exacerbation during the 12-month follow-up were conducted using paired t-tests or a non-parametric equivalent. Multiple linear regression analysis was used to evaluate the independent impact of experiencing an exacerbation (any exacerbation or severe exacerbation) on clinical outcomes at 12 months, controlling for group allocation (home or center-based pulmonary rehabilitation), baseline values (functional capacity, quality of life), age, gender, $\mathrm{FEV}_{1}$ and smoking status. Collinearity was assessed using Variance Inflation Factors and Tolerance Statistics, which confirmed no multicollinearity in the models. Logistic regression was performed to assess predictors of exacerbations in the year following pulmonary rehabilitation. Independent variables of interest were predictors of exacerbations previously identified in a large cohort of patients with $\mathrm{COPD},{ }^{23}$ including $\mathrm{FEV}_{1} \%$ predicted, history of gastro-oesophageal reflux and baseline healthrelated quality of life. Other known predictors of exacerbations (exacerbation history, white cell count) were not available in our dataset. Completion of pulmonary rehabilitation (yes/no) was included as a potential predictor, as this was associated with future hospitalization in our trial. ${ }^{8}$ Separate models were constructed for severe exacerbations, or any exacerbation (moderate or severe).

\section{Results}

Data from 166 participants in the HomeBase trial who completed center-based $(n=86)$ or home-based $(n=80)$ rehabilitation were included. Data were missing for $n=13$ participants who declined to perform one or more tests at the follow-up assessments. ${ }^{8}$ Demographic characteristics of participants are presented in Table 1.

During the year following pulmonary rehabilitation 123 (74\%) participants had at least one exacerbation (moderate or severe combined) and $56(34 \%)$ participants had at least one severe exacerbation requiring hospitalization (Table 1). There was no difference between groups in the risk of having any exacerbation (RR 1.06 [95\% CI 0.89 to 1.26], $\mathrm{p}=0.51$ ) or a severe exacerbation (RR 0.75 [95\% CI 0.48 to 1.16$], p=0.20$ ). Following pulmonary rehabilitation, median [IQR] time to first exacerbation was 48 [15 to 125] days in the HomeBase group compared to 26 [12 to 112] days for the center-based group ( $p=0.93)$, with 
Table I Demographic Characteristics of Participants

\begin{tabular}{|c|c|c|c|}
\hline & $\begin{array}{l}\text { Home- } \\
\text { Based } \\
\text { Group } \\
(n=80)\end{array}$ & $\begin{array}{l}\text { Center- } \\
\text { Based } \\
\text { Group } \\
(n=86)\end{array}$ & $\begin{array}{l}\text { Both } \\
\text { Groups } \\
(n=166)\end{array}$ \\
\hline Age, years & $69.6(9.2)$ & $68.4(9.5)$ & $69.0(9.4)$ \\
\hline Male/female, $\mathrm{n}$ & $48 / 32$ & $51 / 35$ & $99 / 67$ \\
\hline $\mathrm{FEV}_{1}$, litres & I.3 (0.48) & $1.25(0.60)$ & $1.28(0.54)$ \\
\hline $\mathrm{FEV}, \%$ predicted & $49.7(13.4)$ & $40.7(15.6)$ & 49.9 (19.2) \\
\hline $\mathrm{FEV}_{1} / \mathrm{FVC}$ & $0.47(0.16)$ & $0.45(0.14)$ & $46.3(15.1)$ \\
\hline Pack-year, $\mathrm{n}$ & $47(36)$ & $50(29)$ & $49(32)$ \\
\hline Baseline 6MWD, m & $380(121)$ & $411(107)$ & $403(114)$ \\
\hline \multicolumn{4}{|l|}{ mMRC, n (\%) } \\
\hline 0 & $2(3 \%)$ & $0(0 \%)$ & $2(1 \%)$ \\
\hline 1 & $33(4 \mid \%)$ & $36(42 \%)$ & $69(42 \%)$ \\
\hline 2 & $22(28 \%)$ & $28(33 \%)$ & $50(30 \%)$ \\
\hline 3 & $21(26 \%)$ & $19(22 \%)$ & $40(24 \%)$ \\
\hline 4 & $2(3 \%)$ & $3(4 \%)$ & $5(3 \%)$ \\
\hline Any exacerbation, n (\%) & 61 (76\%) & $62(72 \%)$ & $123(74 \%)$ \\
\hline Moderate exacerbation, $\mathrm{n}(\%)$ & 57 (71\%) & $55(64 \%)$ & $112(68 \%)$ \\
\hline Severe exacerbation, $\mathrm{n}$ (\%) & $23(29 \%)$ & $33(38 \%)$ & $56(34 \%)$ \\
\hline
\end{tabular}

Note: Data presented are mean (SD) unless otherwise stated.

Abbreviations: $F E V_{1}$, forced expiratory volume in I second; FVC, forced vital capacity; 6MWD, 6-min walk distance; CRQ, Chronic Respiratory Questionnaire; mMRC, modified Medical Research Council scale.

similar findings for time to first severe exacerbation (median 117 days [30 to 283] vs 128 [31 to 221], $\mathrm{p}=0.18$ ). As there were no significant differences in exacerbation risk between groups, data were combined for subsequent analysis.

Univariate analysis showed that participants who did not experience a severe exacerbation had larger improvements in CRQ fatigue at 12 months following pulmonary rehabilitation compared to those who experienced a severe exacerbation (Table 2). There was no statistically significant difference between those who experienced any exacerbation compared to those who did not for change in functional capacity, health-related quality of life, dyspnea or physical activity from baseline to 12 months after pulmonary rehabilitation (Table 2). Individuals who experienced a severe exacerbation tended to have worse outcomes than those with moderate or no exacerbations; this reached statistical significance only for CRQ fatigue domain (Table 2). However, in multiple linear regression analysis controlling for baseline features (age, gender, $\mathrm{FEV}_{1}$ and smoking status), having a severe exacerbation was an independent predictor of worse outcomes at 12 months following pulmonary rehabilitation for health-related quality of life (CRQ total, fatigue, mastery and emotional function), dyspnea (mMRC), functional capacity (6MWD) and daily physical activity (total MVPA) (Table 3). Age, $\mathrm{FEV}_{1}$, smoking status and group allocation were not independent predictors of 12-month outcomes. Experiencing any

Table 2 Clinical Outcomes at 12 Months After Pulmonary Rehabilitation (Change from Baseline) for Participants with and without Exacerbations During Follow-Up

\begin{tabular}{|c|c|c|c|c|c|c|}
\hline & \multicolumn{3}{|l|}{ Any Exacerbation } & \multicolumn{3}{|l|}{ Severe Exacerbation } \\
\hline & Exacerbation & No Exacerbation & p value & Severe Exacerbation & $\begin{array}{l}\text { No Exacerbation } \\
\text { or Moderate } \\
\text { Exacerbation }\end{array}$ & $p$ value \\
\hline 6MWD, m & II $[-33$ to 49$]$ & $17.5[-34$ to 43$]$ & 0.89 & $0[-76$ to 42$]$ & $17[-22$ to 50$]$ & 0.25 \\
\hline CRQ Dyspnea & I $[-3$ to 7$]$ & $2[-1.5$ to 6$]$ & 0.87 & $0.5[-4$ to 7$]$ & $2[-2$ to 6$]$ & 0.49 \\
\hline CRQ Fatigue & I $[-3$ to 4$]$ & $2[0$ to 5$]$ & 0.21 & $0[-4$ to 3$]$ & $2[-0$ to 5$]$ & 0.03 \\
\hline CRQ Emotional Function & $2[-3$ to 8$]$ & $2[-2$ to 9$]$ & 0.82 & I $[-4.3$ to 7$]$ & $4[-2$ to 8$]$ & 0.10 \\
\hline CRQ Mastery & I $[-1$ to 5$]$ & $2[-1$ to 4.5$]$ & 0.89 & I $[-2$ to 5$]$ & $1.5[-1$ to 5$]$ & 0.35 \\
\hline CRQ Total & $6[-4$ to 18$]$ & $8[-2$ to 21$]$ & 0.54 & $2[-8$ to 18$]$ & $9.5[-2$ to 20$]$ & 0.07 \\
\hline $\mathrm{mMRC}$ & $0[-\mid$ to $I]$ & $0[0$ to I $]$ & 0.76 & $-I[-\mid$ to $I]$ & $0[0$ to I] & 0.18 \\
\hline Total MVPA, min/day & $-131[-373$ to 30$]$ & $61[-169$ to 211$]$ & 0.15 & $-282[-460$ to -26$]$ & $-1[-198$ to 112$]$ & 0.13 \\
\hline $\begin{array}{l}\text { Duration MVPA in } \\
\text { bouts, min/day }\end{array}$ & $-14[-90$ to 5$]$ & $39[-59$ to 138$]$ & 0.14 & $-27[-118$ to 5$]$ & $0[-74$ to 56$]$ & 0.64 \\
\hline $\begin{array}{l}\text { Sedentary awake time, } \\
\mathrm{min} / \text { day }\end{array}$ & $-826[-1605$ to 147$]$ & $-102[-720$ to 398$]$ & 0.28 & $-806[-71,209$ to -23$]$ & $-393[-1225$ to 399$]$ & 0.22 \\
\hline
\end{tabular}

Notes: Data are change from baseline (pre-rehabilitation) to 12 months, median [interquartile range]. p values represent difference between groups who did or did not have an exacerbation.

Abbreviations: 6MWD, 6-minute walk distance; CRQ, Chronic Respiratory Questionnaire; MMRC, modified Medical Research Council scale; MVPA, moderate to vigorous physical activity; Duration MVPA bouts: duration of MVPA when in bouts of at least $10 \mathrm{~min}$. 
Table 3 Multiple Linear Regression Analysis for Impact of Severe Exacerbations During Follow-Up on Clinical Outcomes at 12 Months

\begin{tabular}{|c|c|c|c|c|c|c|}
\hline & Variable & B & $95 \% \mathrm{Cl}$ & Standardised Beta & $\mathbf{p}$ & $\mathbf{R}^{2}$ for Model \\
\hline CRQ Total & $\begin{array}{l}\text { Constant } \\
\text { Severe exacerbation } \\
\text { Group allocation } \\
\text { Age } \\
\text { Gender } \\
\text { FEV } \\
\text { Smoking status } \\
\text { Baseline CRQ Total }\end{array}$ & $\begin{array}{l}46.91 \\
-10.89 \\
0.57 \\
-0.08 \\
1.04 \\
3.69 \\
-0.77 \\
-0.46\end{array}$ & $\begin{array}{l}7.45 \text { to } 86.37 \\
-18.73 \text { to }-3.05 \\
-6.25 \text { to } 7.38 \\
-0.51 \text { to } 0.35 \\
-5.93 \text { to } 8.01 \\
-2.66 \text { to } 10.03 \\
-10.00 \text { to } 8.47 \\
-0.65 \text { to }-0.26\end{array}$ & $\begin{array}{l}-0.243 \\
0.014 \\
-0.034 \\
0.025 \\
0.100 \\
-0.014 \\
-0.422\end{array}$ & $\begin{array}{l}0.02 \\
0.007 \\
0.87 \\
0.71 \\
0.77 \\
0.25 \\
0.87 \\
<0.001\end{array}$ & 0.22 \\
\hline CRQ Dyspnea & $\begin{array}{l}\text { Constant } \\
\text { Severe exacerbation } \\
\text { Group allocation } \\
\text { Age } \\
\text { Gender } \\
\text { FEV } \\
\text { Smoking status } \\
\text { Baseline CRQ Dyspnea }\end{array}$ & $\begin{array}{l}9.21 \\
-1.22 \\
0.06 \\
-0.08 \\
2.47 \\
1.18 \\
-0.90 \\
-0.40\end{array}$ & $\begin{array}{l}-3.21 \text { to } 21.63 \\
-3.67 \text { to } 1.22 \\
-2.11 \text { to } 2.24 \\
-0.21 \text { to } 0.05 \\
0.28 \text { to } 4.66 \\
-0.83 \text { to } 3.20 \\
-3.86 \text { to } 2.06 \\
-0.60 \text { to }-0.19\end{array}$ & $\begin{array}{l}-0.088 \\
0.005 \\
-0.106 \\
0.192 \\
0.103 \\
-0.055 \\
-0.337\end{array}$ & $\begin{array}{l}0.14 \\
0.32 \\
0.96 \\
0.24 \\
0.03 \\
0.25 \\
0.55 \\
<0.001\end{array}$ & 0.19 \\
\hline CRQ Fatigue & $\begin{array}{l}\text { Constant } \\
\text { Severe exacerbation } \\
\text { Group allocation } \\
\text { Age } \\
\text { Gender } \\
\text { FEV } \\
\text { Smoking status } \\
\text { Baseline CRQ Fatigue }\end{array}$ & $\begin{array}{l}10.50 \\
-3.46 \\
0.51 \\
-0.02 \\
-0.24 \\
0.32 \\
0.54 \\
-0.59\end{array}$ & $\begin{array}{l}0.15 \text { to } 20.75 \\
-5.45 \text { to }-1.46 \\
-1.25 \text { to } 2.27 \\
-0.12 \text { to } 0.09 \\
-2.05 \text { to } 1.57 \\
-1.34 \text { to } 1.98 \\
-1.83 \text { to } 2.90 \\
-0.78 \text { to }-0.40\end{array}$ & $\begin{array}{l}-0.283 \\
0.045 \\
-0.023 \\
-0.021 \\
0.031 \\
0.037 \\
-0.507\end{array}$ & $\begin{array}{l}0.05 \\
0.001 \\
0.57 \\
0.78 \\
0.79 \\
0.71 \\
0.45 \\
<0.001\end{array}$ & 0.31 \\
\hline CRQ Emotional & $\begin{array}{l}\text { Constant } \\
\text { Severe exacerbation } \\
\text { Group allocation } \\
\text { Age } \\
\text { Gender } \\
\text { FEV } \\
\text { Smoking status } \\
\text { Baseline CRQ Emotional }\end{array}$ & $\begin{array}{l}17.950 \\
-4.61 \\
0.06 \\
0.02 \\
-1.33 \\
1.15 \\
0.57 \\
-0.48\end{array}$ & $\begin{array}{l}3.688-32.211 \\
-7.45 \text { to }-1.77 \\
-2.41 \text { to } 2.53 \\
-0.14 \text { to } 0.17 \\
-3.87 \text { to } 1.20 \\
-1.16 \text { to } 3.47 \\
-2.77 \text { to } 3.90 \\
-0.63 \text { to }-0.32\end{array}$ & $\begin{array}{l}-0.270 \\
0.004 \\
0.019 \\
-0.084 \\
0.082 \\
0.028 \\
-0.533\end{array}$ & $\begin{array}{l}0.01 \\
0.002 \\
0.96 \\
0.83 \\
0.30 \\
0.33 \\
0.74 \\
<0.001\end{array}$ & 0.30 \\
\hline CRQ Mastery & $\begin{array}{l}\text { Constant } \\
\text { Severe exacerbation } \\
\text { Group allocation } \\
\text { Age } \\
\text { Gender } \\
\text { FEV } \\
\text { Smoking status } \\
\text { Baseline CRQ Mastery }\end{array}$ & $\begin{array}{l}10.80 \\
-1.93 \\
-0.13 \\
0.03 \\
-0.20 \\
0.95 \\
-1.01 \\
-0.53\end{array}$ & $\begin{array}{l}0.87 \text { to } 20.74 \\
-3.89 \text { to } 0.04 \\
-1.88 \text { to } 1.61 \\
-0.08 \text { to } 0.14 \\
-1.88 \text { to } 1.64 \\
-0.70 \text { to } 2.59 \\
-3.35 \text { to } 1.33 \\
-0.70 \text { to }-0.36\end{array}$ & $\begin{array}{l}-0.163 \\
-0.012 \\
0.045 \\
-0.011 \\
0.097 \\
-0.072 \\
-0.535\end{array}$ & $\begin{array}{l}0.03 \\
0.05 \\
0.88 \\
0.62 \\
0.89 \\
0.26 \\
0.40 \\
<0.001\end{array}$ & 0.28 \\
\hline 6MWD & $\begin{array}{l}\text { Constant } \\
\text { Severe exacerbation }\end{array}$ & $\begin{array}{l}94.56 \\
-36.49\end{array}$ & $\begin{array}{l}-93.25 \text { to } 282.37 \\
-71.69 \text { to }-1.27\end{array}$ & -0.205 & $\begin{array}{l}0.32 \\
0.04\end{array}$ & 0.08 \\
\hline
\end{tabular}

(Continued) 
Table 3 (Continued).

\begin{tabular}{|c|c|c|c|c|c|c|}
\hline & Variable & B & $95 \% \mathrm{Cl}$ & Standardised Beta & $\mathbf{p}$ & $\mathbf{R}^{2}$ for Model \\
\hline & $\begin{array}{l}\text { Group allocation } \\
\text { Age } \\
\text { Gender } \\
\text { FEV } \\
\text { Smoking status } \\
\text { Baseline 6MWD }\end{array}$ & $\begin{array}{l}14.13 \\
-1.14 \\
7.44 \\
18.29 \\
-2.76 \\
-0.14\end{array}$ & $\begin{array}{l}-15.99 \text { to } 22.24 \\
-2.97 \text { to } 0.69 \\
-23.43 \text { to } 38.32 \\
-12.86 \text { to } 49.440 \\
-43.06 \text { to } 37.54 \\
-0.30 \text { to } 0.01\end{array}$ & $\begin{array}{l}0.089 \\
-0.128 \\
0.047 \\
0.128 \\
-0.014 \\
-0.197\end{array}$ & $\begin{array}{l}0.35 \\
0.22 \\
0.63 \\
0.25 \\
0.89 \\
0.07\end{array}$ & \\
\hline MMRC & $\begin{array}{l}\text { Constant } \\
\text { Severe exacerbation } \\
\text { Group allocation } \\
\text { Age } \\
\text { Gender } \\
\text { FEV }_{\text {, }} \\
\text { Smoking status } \\
\text { Baseline MMRC }\end{array}$ & $\begin{array}{l}2.41 \\
0.58 \\
0.20 \\
-0.00 \\
-0.55 \\
-0.26 \\
-0.14 \\
-0.64\end{array}$ & $\begin{array}{l}0.01 \text { to } 4.81 \\
0.12 \text { to } 1.03 \\
-0.20 \text { to } 0.61 \\
-0.03 \text { to } 0.02 \\
-0.96 \text { to }-0.15 \\
-0.65 \text { to } 0.13 \\
-0.67-\text { to } 0.40 \\
-0.89 \text { to }-0.39\end{array}$ & $\begin{array}{l}0.219 \\
0.084 \\
-0.018 \\
-0.227 \\
-0.117 \\
-0.044 \\
-0.445\end{array}$ & $\begin{array}{l}0.05 \\
0.01 \\
0.317 \\
0.83 \\
0.008 \\
0.20 \\
0.615 \\
<0.001\end{array}$ & 0.23 \\
\hline Total MVPA & $\begin{array}{l}\text { Constant } \\
\text { Severe exacerbation } \\
\text { Group allocation } \\
\text { Age } \\
\text { Gender } \\
\text { FEV } \\
\text { Smoking status } \\
\text { Baseline MVPA Total }\end{array}$ & $\begin{array}{l}-34.28 \\
-371.26 \\
77.10 \\
-3.30 \\
-52.25 \\
-86.83 \\
382.39 \\
-0.27\end{array}$ & $\begin{array}{l}-1296.02 \text { to } 1227.46 \\
-724.99 \text { to }-17.54 \\
-201.54 \text { to } 355.75 \\
-18.09 \text { to } 11.50 \\
-295.85 \text { to } 191.36 \\
-371.14 \text { to } 197.48 \\
76.04 \text { to } 688.73 \\
-0.49 \text { to }-0.05\end{array}$ & $\begin{array}{l}-0.462 \\
0.109 \\
-0.087 \\
-0.073 \\
-0.116 \\
0.457 \\
-0.468\end{array}$ & $\begin{array}{l}0.96 \\
0.04 \\
0.58 \\
0.65 \\
0.66 \\
0.54 \\
0.16 \\
0.18\end{array}$ & 0.32 \\
\hline Duration MVPA Bouts & $\begin{array}{l}\text { Constant } \\
\text { Severe exacerbation } \\
\text { Group allocation } \\
\text { Age } \\
\text { Gender } \\
\text { FEV } \\
\text { Smoking status } \\
\text { Baseline MVPA bouts }\end{array}$ & $\begin{array}{l}360.16 \\
-147.15 \\
14.60 \\
-5.05 \\
-33.21 \\
-90.17 \\
137.96 \\
-0.15\end{array}$ & $\begin{array}{l}-335.5 \text { to } 1055.77 \\
-354.67 \text { to } 60.37 \\
-146.13 \text { to } 175.31 \\
-13.40 \text { to } 3.30 \\
-172.84 \text { to } 106.43 \\
-254.02 \text { to } 73.67 \\
-50.02 \text { to } 325.93 \\
-0.396 \text { to } 0.11\end{array}$ & $\begin{array}{l}-0.347 \\
0.039 \\
-0.252 \\
-0.088 \\
-0.228 \\
0.313 \\
-0.252\end{array}$ & $\begin{array}{l}0.30 \\
0.16 \\
0.85 \\
0.23 \\
0.63 \\
0.27 \\
0.14 \\
0.25\end{array}$ & 0.18 \\
\hline Total Sedentary time & $\begin{array}{l}\text { Constant } \\
\text { Severe exacerbation } \\
\text { Group allocation } \\
\text { Age } \\
\text { Gender } \\
\mathrm{FEV}_{\text {, }} \\
\text { Smoking status } \\
\text { Baseline sedentary time }\end{array}$ & $\begin{array}{l}3261.29 \\
-|44.4| \\
-204.73 \\
15.86 \\
-431.30 \\
50.0 \mid \\
-264.27 \\
-0.76\end{array}$ & $\begin{array}{l}-2033.07 \text { to } 8555.65 \\
-1665.39 \text { to } 1376.57 \\
-1519.82 \text { to } 1110.37 \\
-64.34 \text { to } 96.05 \\
-1583.6 \mid \text { to } 721.01 \\
-1134.80 \text { to } 1234.82 \\
-1586.18 \text { to } 1057.64 \\
-1.39 \text { to }-0.14\end{array}$ & $\begin{array}{l}-0.043 \\
-0.069 \\
0.099 \\
-0.143 \\
0.016 \\
-0.075 \\
0.306\end{array}$ & $\begin{array}{l}0.22 \\
0.85 \\
0.75 \\
0.69 \\
0.45 \\
0.93 \\
0.69 \\
0.02\end{array}$ & 0.26 \\
\hline
\end{tabular}

Notes: Dependent variables are change from baseline to 12 months following pulmonary rehabilitation. Severe exacerbation during follow-up is coded as $0=$ no, $\mathrm{I}=$ yes; Pulmonary rehabilitation group is coded as $\mathrm{I}=$ home-based, 2 = center-based; Age is measured in years; FEV is measured in litres; Smoking status is coded as $0=$ never smoked or quit, $\mathrm{I}$ = current smoking.

Abbreviations: 6MWD, 6-minute walk distance; $\mathrm{Cl}$, confidence interval for B; CRQ, Chronic Respiratory Questionnaire; FEV 1 , forced expiratory volume in one second; MVPA, moderate to vigorous intensity physical activity.

exacerbation (moderate or severe) was not an independent predictor of clinical outcomes at 12 months following pulmonary rehabilitation (Table S2).
Participants who completed pulmonary rehabilitation (attending at least $70 \%$ of sessions) were significantly less likely to have a severe exacerbation in the following 
Table 4 Logistic Regression Predicting Likelihood of Having Severe Exacerbation 12 Months After Pulmonary Rehabilitation

\begin{tabular}{|c|c|c|c|c|c|}
\hline & B & SE & $\mathbf{p}$ & $\begin{array}{l}\text { Odds } \\
\text { Ratio }\end{array}$ & $95 \% \mathrm{Cl}$ \\
\hline $\begin{array}{l}\text { Pulmonary } \\
\text { rehabilitation } \\
\text { completion }\end{array}$ & -0.624 & 0.384 & 0.10 & 0.536 & $0.252-1.138$ \\
\hline History of GOR & 0.419 & 0.369 & 0.26 & 1.520 & $0.738-3.131$ \\
\hline $\mathrm{FEV}, \%$ predicted & -0.033 & 0.011 & 0.002 & 0.968 & $0.948-0.988$ \\
\hline $\begin{array}{l}\text { CRQ Total at baseline } \\
\text { Constant }\end{array}$ & -0.024 & 0.010 & 0.01 & 0.976 & $0.957-0.994$ \\
\hline
\end{tabular}

Notes: Severe exacerbation during follow-up is coded as $0=$ no, $\mathrm{I}=$ yes: Pulmonary completion is coded as $0=$ no, $\mathrm{I}=$ yes.

Abbreviations: $\mathrm{Cl}$, confidence interval for odds ratio; $\mathrm{CRQ}$, Chronic Respiratory Questionnaire; $\mathrm{FEV}_{1}$, forced expiratory volume in one second; GOR, gastroesophageal reflux.

12 months ( $29 \%$ vs $48 \%, \mathrm{p}=0.02)$. Aside from program completion, the initial response to pulmonary rehabilitation at 8 weeks did not differ between patients with and without a subsequent exacerbation, regardless of exacerbation severity (Table S3). A logistic regression model showed that for every 10-point increase in CRQ total score at baseline, the odds of a severe exacerbation were reduced by $24 \%(\mathrm{p}=0.01)$. For every $10 \%$ increase in $\mathrm{FEV}_{1} \%$ predicted at baseline, the odds of a severe exacerbation were reduced by $32 \%(\mathrm{p}=0.002$, Table 4$)$. Pulmonary rehabilitation completion reduced the odds of a severe exacerbation by $46 \%$, but this did not reach statistical significance $(\mathrm{p}=0.10)$.

\section{Discussion}

This secondary analysis of a clinical trial data shows that exacerbations are common in people with COPD in the year following pulmonary rehabilitation, with severe exacerbations occurring in one-third of our sample. Those who experienced severe exacerbations had worse 12month outcomes for health-related quality of life, symptoms, exercise capacity and daily physical activity. Severe exacerbations were more likely in those who had entered pulmonary rehabilitation with lower respiratory function and poorer health-related quality of life. Those who are unable to complete $70 \%$ of their pulmonary rehabilitation sessions may also be at higher risk of severe exacerbation in the year following the program.

The number of patients experiencing at least one COPD exacerbation requiring hospitalization (34\%) was high in our study. Recent clinical trials and cohort studies have reported that over 12 months less than $15 \%$ of participants experience a severe exacerbation requiring hospitalization. ${ }^{24,25}$ Consistent with the features of patients who are typically referred to pulmonary rehabilitation, our participants had high symptom burden and low functional capacity. They may therefore represent a different subset of the COPD population to those commonly enrolled in trials of pharmaceutical treatments or cohorts. Although there is some evidence that pulmonary rehabilitation may reduce subsequent hospitalization, particularly when delivered after an exacerbation, ${ }^{26}$ the results of the current study suggest that pulmonary rehabilitation participants remain at high risk of hospitalization in the year following the program. We also reported high numbers of moderate exacerbations requiring a change in treatment without hospitalisation; the use of administrative data to identify all new prescriptions of oral corticosteroids and antibiotics may have contributed to this finding.

Maintaining the benefits of pulmonary rehabilitation over time has been called the 'holy grail' of pulmonary rehabilitation research. ${ }^{27}$ Our results highlight the important impact of severe exacerbations on the long-term outcomes of pulmonary rehabilitation. A previous study has examined the exacerbations in the six months following pulmonary rehabilitation, demonstrating a reduction in exercise capacity and reduced health-related quality of life at two weeks following exacerbation onset. ${ }^{28}$ Our study extends this work, showing that patients experiencing a severe exacerbation at any time in the year following pulmonary rehabilitation do have limited recovery, with worse outcomes at 12 months than their peers who do not experience an exacerbation. These data suggest that strategies to maintain the benefits of pulmonary rehabilitation are unlikely to be successful unless exacerbation risk is addressed. The best method by which this might be achieved is unclear. Existing maintenance strategies, generally consisting of supervised exercise programs offered at a lower frequency than the initial pulmonary rehabilitation program, do not appear effective. ${ }^{9}$ These maintenance strategies commonly focus on exercise training, delivered at a lower dose than the initial program; such programs may or may not include support for self-management, including early identification and treatment of exacerbations. A more targeted approach for those experiencing exacerbations may be required.

Predicting which individuals will experience an exacerbation in the year after pulmonary rehabilitation is challenging but important, in terms of both for targeting preventative efforts and for intervening to improve outcomes. Previous authors have reported predictors of exacerbations during 
a 4-week pulmonary rehabilitation program, ${ }^{29}$ but the predictors of exacerbations in the following year have not been studied. Not surprisingly our data indicate that pulmonary rehabilitation participants with more severe lung disease and worse health-related quality of life are at higher risk of exacerbation. Failure to complete pulmonary rehabilitation may also be important, reinforcing the need to support patients with COPD to attend regularly (or participate regularly if they are doing the home-based program) and to finish the program. During pulmonary rehabilitation, strategies to enhance self-management skills may be valuable to optimise identification and treatment of exacerbations. A recent study highlighted the potential of exacerbation action plans to reduce respiratory-related hospitalization in people with COPD and comorbidities (including at least one of ischaemic heart disease, heart failure, diabetes, anxiety or depression). ${ }^{30}$ Participants in our study had a median of four comorbid conditions, ${ }^{8}$ so this strategy warrants further examination. In patients who have experienced a severe exacerbation, it may be useful to re-enrol in pulmonary rehabilitation. There is some evidence that repeat programs are effective in reversing decline in exercise capacity and may ameliorate worsening symptoms. ${ }^{31}$ Nonetheless, given the welldocumented challenges in enrolling patients with COPD in pulmonary rehabilitation immediately following an exacerbation, ${ }^{32}$ it may be more fruitful to repeat pulmonary rehabilitation once clinical stability is regained.

Strengths of this study include the relatively large sample of participants with COPD who are typical of those referred to outpatient pulmonary rehabilitation in many centers; 12 months of follow-up; and detailed data on health-care utilisation over 12 months, allowing exacerbations to be ascertained. Limitations include the absence of data on exacerbation history prior to pulmonary rehabilitation, which is a powerful predictor of future exacerbations, ${ }^{23}$ the small number of participants with physical activity data; and the post-hoc nature of the analysis.

In conclusion, exacerbations of COPD occur commonly in the year following pulmonary rehabilitation. Experiencing a severe exacerbation requiring hospitalization is an independent predictor of worse outcomes at 12 months following pulmonary rehabilitation for health-related quality of life, symptoms, exercise capacity and daily physical activity. These findings can be used to inform future research aimed at maintaining the benefits of pulmonary rehabilitation following program completion.

\section{Abbreviations}

6MWD, six-minute walk distance; AECOPD, acute exacerbation of COPD; COPD, chronic obstructive pulmonary disease; CRQ, Chronic Respiratory Questionnaire; $\mathrm{FEV}_{1}$, forced expiratory volume in one second; FVC, forced vital capacity; GOLD, Global Initiative for Chronic Obstructive Lung Disease; HRQoL, healthrelated quality of life; IQR, interquartile range; mMRC, modified Medical Research Council; MVPA, moderate-to-vigorous physical activity; OCS, oral corticosteroids; OR, odds ratio; RR, risk relative; $\mathrm{SD}$, standard deviation.

\section{Data Sharing Statement}

Deidentified individual participant data will be available to investigators whose proposed use of the data has been approved by the responsible human ethics committee. Dataset are available from the corresponding author (Anne E Holland a.holland@alfred.org.au) on reasonable request.

\section{Funding}

B Wageck is the recipient of a full fee research scholarship (LTUFFRs) and postgraduate research scholarships (LTUPRS) from La Trobe University, Melbourne, Australia.

\section{Disclosure}

Christine F McDonald reports speaker fees paid to their institution from Menarini and AstraZeneca, outside the submitted work. The authors report no other potential conflicts of interest for this work.

\section{References}

1. Vestbo J, Hurd SS, Agusti AG, et al. Global strategy for the diagnosis, management, and prevention of chronic obstructive pulmonary disease: GOLD executive summary. Am J Respir Crit Care Med. 2013;187(4):347-365. doi:10.1164/rccm.201204-0596PP

2. Piquet J, Chavaillon JM, David P, et al. High-risk patients following hospitalisation for an acute exacerbation of COPD. Eur Respir J. 2013;42(4):946-955. doi:10.1183/09031936.00180312

3. Soler-Cataluna JJ, Martinez-Garcia MA, Roman Sanchez P, Salcedo E, Navarro M, Ochando R. Severe acute exacerbations and mortality in patients with chronic obstructive pulmonary disease. Thorax. 2005;60 (11):925-931. doi:10.1136/thx.2005.040527

4. Global strategy for the diagnosis, management, and prevention of chronic obstructive lung disease 2017 report: gold executive summary. GOLD. Published 2020. Accessed, 2020.

5. Celli BR, Decramer M, Wedzicha JA, et al. An official american thoracic society/european respiratory society statement: research questions in chronic obstructive pulmonary disease. Am J Respir Crit Care Med. 2015;191(7):e4-e27. doi:10.1164/rccm.201501-0044ST 
6. McCarthy B, Casey D, Devane D, Murphy K, Murphy E, Lacasse Y. Pulmonary rehabilitation for chronic obstructive pulmonary disease. Cochrane Database Systematic Rev. 2015;2:Cd003793.

7. Griffiths TL, Burr ML, Campbell IA, et al. Results at 1 year of outpatient multidisciplinary pulmonary rehabilitation: a randomised controlled trial. Lancet. 2000;355(9201):362-368. doi:10.1016/ S0140-6736(99)07042-7

8. Holland AE, Mahal A, Hill CJ, et al. Home-based rehabilitation for COPD using minimal resources: a randomised, controlled equivalence trial. Thorax. 2017;72(1):57-65. doi:10.1136/thoraxjnl-2016208514

9. Alison JA, McKeough ZJ, Johnston K, et al. Australian and new zealand pulmonary rehabilitation guidelines. Respirology. 2017;22 (4):800-819. doi:10.1111/resp.13025

10. Holland AE, Mahal A, Hill CJ, et al. Benefits and costs of home-based pulmonary rehabilitation in chronic obstructive pulmonary disease - a multi-centre randomised controlled equivalence trial. BMC Pulm Med. 2013;13:57. doi:10.1186/1471-2466-13-57

11. Wageck B, Cox NS, Holland AE. Recovery following acute exacerbations of chronic obstructive pulmonary disease - a review. Copd. 2019;16(1):93-103. doi:10.1080/15412555.2019.1598965

12. Spruit MA, Singh SJ, Garvey C, et al. An official American Thoracic Society/European Respiratory Society statement: key concepts and advances in pulmonary rehabilitation. Am J Respir Crit Care Med. 2013;188(8):e13-64.

13. Burge S, Wedzicha JA. COPD exacerbations: definitions and classifications. Eur Respir J Suppl. 2003;41:46s-53s. doi:10.1183/ 09031936.03.00078002

14. Rodriguez-Roisin R. Toward a consensus definition for COPD exacerbations. Chest. 2000;117(5Suppl 2):398S-401S. doi:10.1378/ chest.117.5 suppl 2.398S

15. van den Berge M, Hop WC, van der Molen T, et al. Prediction and course of symptoms and lung function around an exacerbation in chronic obstructive pulmonary disease. Respir Res. 2012;13:44. doi:10.1186/1465-9921-13-44

16. Vogelmeier CF, Criner GJ, Martinez FJ, et al. Global strategy for the diagnosis, management, and prevention of chronic obstructive lung disease 2017 report. gold executive summary. Am J Respir Crit Care Med. 2017;195(5):557-582. doi:10.1164/rccm.201701-0218PP

17. Dalal AA, Patel J, D'Souza A, Farrelly E, Nagar S, Shah M. Impact of COPD exacerbation frequency on costs for a managed care population. J Manag Care Spec Pharm. 2015;21(7):575-583.

18. Holland AE, Spruit MA, Troosters T, et al. An official European Respiratory Society/American Thoracic Society technical standard: field walking tests in chronic respiratory disease. Eur Respir J. 2014;44(6):1428-1446. doi:10.1183/09031936.00150314

19. Williams JE, Singh SJ, Sewell L, Guyatt GH, Morgan MD. Development of a self-reported Chronic Respiratory Questionnaire (CRQ-SR). Thorax. 2001;56(12):954-959. doi:10.1136/thorax.56. 12.954
20. Bestall JC, Paul EA, Garrod R, Garnham R, Jones PW, Wedzicha JA. Usefulness of the Medical Research Council (MRC) dyspnoea scale as a measure of disability in patients with chronic obstructive pulmonary disease. Thorax. 1999;54(7):581-586. doi:10.1136/thx.54. 7.581

21. Hill K, Dolmage TE, Woon L, Goldstein R, Brooks D. Measurement properties of the SenseWear armband in adults with chronic obstructive pulmonary disease. Thorax. 2010;65(6):486-491. doi:10.1136/ thx.2009.128702

22. Haskell WL, Lee IM, Pate RR, et al. Physical activity and public health: updated recommendation for adults from the American College of Sports Medicine and the American Heart Association. Med Sci Sports Exerc. 2007;39(8):1423-1434. doi:10.1249/mss.0b $013 \mathrm{e} 3180616 \mathrm{~b} 27$

23. Hurst JR, Vestbo J, Anzueto A, et al. Susceptibility to exacerbation in chronic obstructive pulmonary disease. N Engl J Med. 2010;363 (12):1128-1138. doi:10.1056/NEJMoa0909883

24. Andreas S, Rover C, Heinz J, Straube S, Watz H, Friede T. Decline of COPD exacerbations in clinical trials over two decades - a systematic review and meta-regression. Respir Res. 2019;20(1):186. doi:10.11 86/s12931-019-1163-2

25. Wilkinson TMA, Aris E, Bourne SC, et al. Drivers of year-to-year variation in exacerbation frequency of COPD: analysis of the AERIS cohort. ERJ Open Res. 2019;5:1. doi:10.1183/23120541.00248-2018

26. Puhan MA, Gimeno-Santos E, Cates CJ, Troosters T. Pulmonary rehabilitation following exacerbations of chronic obstructive pulmonary disease. Cochrane Database Syst Rev. 2016;12:CD005305.

27. Rochester CL, Spruit MA. Maintaining the benefits of pulmonary rehabilitation. the holy grail. Am J Respir Crit Care Med. 2017;195 (5):548-551. doi:10.1164/rccm.201609-1925ED

28. Carr SJ, Goldstein RS, Brooks D. Acute exacerbations of COPD in subjects completing pulmonary rehabilitation. Chest. 2007;132 (1):127-134. doi:10.1378/chest.07-0269

29. Herer B, Chinet T. Acute exacerbation of COPD during pulmonary rehabilitation: outcomes and risk prediction. Int J Chron Obstruct Pulmon Dis. 2018;13:1767-1774. doi:10.2147/COPD.S163472

30. Lenferink A, van der Palen J, van der Valk P, et al. Exacerbation action plans for patients with COPD and comorbidities: a randomised controlled trial. Eur Respir J. 2019;54:5. doi:10.1183/139930 03.02134-2018

31. Foglio K, Bianchi L, Bruletti G, et al. Seven-year time course of lung function, symptoms, health-related quality of life, and exercise tolerance in COPD patients undergoing pulmonary rehabilitation programs. Respir Med. 2007;101(9):1961-1970. doi:10.1016/j.rmed. 2007.04.007

32. Jones SE, Green SA, Clark AL, et al. Pulmonary rehabilitation following hospitalisation for acute exacerbation of COPD: referrals, uptake and adherence. Thorax. 2014;69(2):181-182. doi:10.1136/ thoraxjnl-2013-204227

International Journal of Chronic Obstructive Pulmonary Disease

Dovepress

\section{Publish your work in this journal}

The International Journal of COPD is an international, peer-reviewed journal of therapeutics and pharmacology focusing on concise rapid reporting of clinical studies and reviews in COPD. Special focus is given to the pathophysiological processes underlying the disease, intervention programs, patient focused education, and self management protocols. This journal is indexed on PubMed Central, MedLine and CAS. The manuscript management system is completely online and includes a very quick and fair peer-review system, which is all easy to use. Visit http://www.dovepress.com/testimonials.php to read real quotes from published authors. 